\title{
Regional inequality and product variety
}

K. Behrens and J.F. Thisse

Discussion Paper 2005-13

Département des Sciences Économiques

de l'Université catholique de Louvain 


\title{
Regional inequality and product variety*
}

\author{
Kristian Behrens $^{\dagger} \quad$ Jacques-François Thisse $^{\ddagger}$
}

January 23, 2005

\begin{abstract}
We investigate how differences in set-up costs of various types affect the trade-off between global efficiency and spatial equity and show that the standard assumption of symmetry in fixed costs masks the existence of an interesting effect: the range of available varieties varies depends on the spatial distribution of firms. In such a setting, even when the market outcome leads to excessive agglomeration under symmetric fixed costs, a planner opts for asymmetric fixed costs and more agglomeration. The reason is that the losses induced by more agglomeration are offset by the gains due to additional product variety.
\end{abstract}

Keywords: fixed costs; set-up costs; market size; international trade; home market effect

JEL Classification: F12; F15; R12; R38

\footnotetext{
${ }^{*}$ We wish to thank Isabelle Grilo, Gianmarco Ottaviano and Pierre Picard for valuable comments and suggestions.

${ }^{\dagger}$ CORE, Université catholique de Louvain, Belgium. Email: behrens@core.ucl.ac. be

${ }^{\ddagger}$ CORE, Université catholique de Louvain, Belgium; CERAS, Ecole Nationale des Ponts et Chaussées, France; and CEPR. Email: thisse@core.ucl.ac.be
} 


\section{Introduction}

There are multiple costs associated with the launching of a new business. They range from fixed production costs, specialized infrastructure (such as those needed to load and unload cargo) and land on which plants are built, on the one end of the spectrum, to legal procedures, registration fees and administrative delays, on the other. There is no doubt that all these costs considerably vary across countries. Besides differences in technologies and land rents, administrative set-up costs also exhibit a high degree of variation. Indeed, as observed by Djankov et al. (2002, p. 1) "for starting to operate a business in Mozambique, an entrepreneur must complete 19 procedures taking at least 149 business days and pay US $\$ 256$ in fees. To do the same, an entrepreneur in Italy needs to follow 16 different procedures, pay US $\$ 3,946$ in fees and wait at least 62 business days to acquire the necessary permits. In contrast, an entrepreneur in Canada can finish the process in 2 days by paying US $\$ 280$ in fees and completing only 2 procedures".

Low set-up costs and easy entry for firms seem to be a significant determinant of entrepreneurial dynamism, international location decisions, and economic performance in general (GEM, 2002; European Commission, 2002). Hence, an 'entrepreneurial deficit' due to complicated and costly entry may constitute an important handicap for a country, damaging its long-run economic development. This is clearly recognized by the European Commission, which recently pointed out that the most important reasons for the European Union's (henceforth, EU) perceived 'entrepreneurial deficit' are as follows: "it is the combination of lengthy and complex procedures and significant cost and capital requirements that is likely to act as the greatest barrier to the formation of new Private Limited Companies" (European Commission, 2002, p. 75). Further, it is a well-know fact that there are less 'business angels' and venture capital in Europe, thus making the creation of high risk start-ups potentially more difficult than in the US. For example, in 1999, total venture capital invested in the US amounted to US $\$ 40.6$ billion, whereas the corresponding figure for Europe was only US $\$ 10.8$ billion (GEM, 2000, p. 46).

In this paper, we investigate how differences in set-up costs of various types affect the trade-off between global efficiency and spatial equity in an increasingly integrated space-economy such as the EU (Ottaviano and Thisse, 2002). To do so, we build on the observation that differences in technologies and factor endowments between EU countries are relatively small, whereas differences in set-up and entry costs, as well as in entrepreneurial dynamism and business culture, remain relatively large (European Commission, 2002; 
GEM, 2000). This suggests to focus on a setting in which variable production costs are the same across countries, whereas fixed and entry costs differ between them. More concretely, we develop a two-country model of trade with mobile capital, which incorporates both differences in market size as well as in set-up costs within the same framework. This allows us to evaluate their relative importance in generating spatial patterns of production and trade. It is worth noting that the standard assumption of symmetry in set-up costs masks the existence of an interesting effect: the range of available varieties varies with the spatial distribution of firms when they do not operate under identical fixed costs in both countries. When fixed costs are the same across countries, we will see that the market outcome always leads to excessive agglomeration. Yet, when the planner can choose to make these fixed costs asymmetric, she quite surprisingly opts in favor of stronger spatial inequalities because the welfare loss associated with them is more than offset in terms of gains due to product variety. Hence, more agglomeration may be socially desirable when compared with the symmetric setting, even in the absence of purely Marshallian externalities that play a central role in explaining the spatial concentration of activity (Krugman, 1991).

The secondary purpose of this paper is to asses the robustness of the prediction known as the 'home market effect' (henceforth, HME): everything else being equal, large countries attract a more than proportional share of firms in industries characterized by imperfect competition, increasing returns to scale, and trade costs (Krugman, 1980; Helpman and Krugman, 1985; Head et al., 2002). Our results show that differences in fixed costs may dampen the HME, a direct implication of this being that the harmonization promoted by the European Commission may well exacerbate economic differences between countries when they differ sufficiently in size. Since size is obviously one of the few aspects that are definitely beyond the reach of harmonization, somewhat paradoxically, countries may well become more different the less different they strive to become. This question is part of the larger debate on whether harmonization in general (e.g., tax rates, fiscal policy, institutional aspects) may lead to an increasing polarization of the economic landscape, a question that has recently become even more pressing in the wake of the EU's eastern enlargement.

The remainder of the paper is structured as follows. In Section 2, we present the model. Section 3 discusses the market outcome and shows that a mean-preserving deviation in fixed costs in favor of the smaller country decreases the total mass of varieties produced in the global economy. Section 4 then analyzes the first-best outcome and shows that the market outcome provides excessive agglomeration under symmetric fixed costs, whereas 
the planner will choose to increase agglomeration in the asymmetric setting because consumers have access to a wider array of varieties. Section 5 concludes.

\section{The model}

Consider an economy formed by 2 countries, labeled $H$ and $F$, and a unit mass of consumers. We choose the units of labor and capital for each consumer to be endowed with one unit of labor and one unit of capital. Let $0<\theta<1$ denote the share (and mass) of consumers, labor, and capital in country $H$. Because we rule out the case of symmetric countries, we may assume that $\theta>1 / 2$, i.e., $H$ is the large country. Consumers are immobile and supply labor locally, whereas capital is perfectly mobile and can be supplied anywhere. While $\theta$ is exogenously given, the share $0 \leq \lambda \leq 1$ of capital invested in country $H$ is determined endogenously.

All consumers have the same quasi-linear preferences with quadratic subutility over the consumption of two types of goods, a homogeneous good $Z$ and a continuum of mass $N$ of horizontally differentiated varieties (Ottaviano et al., 2002). A consumer of country $i=H, F$ solves the following problem:

$$
\left\{\begin{aligned}
& \max _{q_{i}(v), v \in[0, N] ; Z} \alpha \int_{0}^{N} q_{i}(v) \mathrm{d} v-\frac{\beta-\gamma}{2} \int_{0}^{N}\left[q_{i}(v)\right]^{2} \mathrm{~d} v-\frac{\gamma}{2}\left[\int_{0}^{N} q_{i}(v) \mathrm{d} v\right]^{2}+Z_{i} \\
& \text { s.t. } \int_{0}^{N} p_{i}(v) q_{i}(v) \mathrm{d} v+p_{i}^{Z} Z_{i}=r_{i}+w_{i}+p_{i}^{Z} \bar{Z}_{0}
\end{aligned}\right.
$$

where $q_{i}(v)$ and $p_{i}(v)$ are the consumption and price of variety $v ; Z_{i}$ and $p_{i}^{Z}$ are the consumption and price of the homogeneous good; $r_{i}$ is the rental rate of capital; $w_{i}$ is the wage; $\alpha>0, \beta>\gamma>0$ are utility parameters.

Turning to technologies, good $Z$ is produced under constant returns and perfect competition with labor as the only input. Without loss of generality, we normalize the unit input requirement to 1 . Each differentiated variety is produced under increasing returns to scale and monopolistic competition with a constant marginal requirement $m$ of labor and a country-specific fixed requirement $\phi_{i}$ of capital. The difference in fixed capital requirement $\phi_{H}-\phi_{F}$ can be thought of as approximating the differences in set-up costs and entry conditions.

In what follows, we denote by $n_{i}$ the mass of firms located in country $i=H, F$. Due to the fixed input requirement, capital market clearing in the 
two countries requires that the masses of firms be as follows:

$$
n_{H}=\frac{\lambda K}{\phi_{H}} \quad \text { and } \quad n_{F}=\frac{(1-\lambda) K}{\phi_{F}}
$$

where $K$ is the total mass of capital available in the global economy. Note that, contrary to Krugman (1980) or Ottaviano and Thisse (2004), the mass of firms in the global economy $\left(N=n_{H}+n_{F}\right)$ changes with the spatial allocation of capital between the two countries. In particular, the market allows for the widest (resp., narrowest) range of varieties when the whole amount of capital is allocated to the low (resp., large) fixed requirement country.

Finally, while good $Z$ is costlessly traded, international shipments of any variety of the differentiated good incur a trade cost of $\tau \geq 0$ units of good $Z$ per unit of variety shipped. As markets are spatially separated, we assume that they are segmented, which means that firms are free to choose how much to sell on each market independently (Haskel and Wolf, 2001). Even within fairly well-integrated blocks, such as the EU or Canada/US, border effects remain strong (Head and Mayer, 2000; Engel and Rogers, 1996), thus justifying our assumption.

Because consumers are indifferent about the origin of varieties, all varieties sold in each country may be treated in a symmetric way. Let $q_{i j}$ denote the quantity of a variety produced in country $i$ bought by a consumer residing in country $j$. The inverse demands in countries $H$ and $F$ for a variety produced in country $H$ can then be expressed as follows:

$$
\begin{aligned}
p_{H H} & =\alpha-(\beta-\gamma) q_{H H}-\gamma Q_{H} \\
p_{H F} & =\alpha-(\beta-\gamma) q_{H F}-\gamma Q_{F}
\end{aligned}
$$

where $Q_{i} / N \equiv n_{i} q_{i i}+n_{j} q_{j i}$ is the average quantity of the differentiated good sold in country $i=H, F$ and $j \neq i$. Due to perfect competition in the $Z$ sector, $p_{i}^{Z}=w_{i}=p^{Z}$ for $i=H, F{ }^{1}$ This makes good $Z$ a convenient choice for the numéraire so that $w_{i}=p^{Z}=1$.

Turning to the differentiated good, because of increasing returns to scale and no economies of scope each firm produces one and only one variety. In our setting, firms play a noncooperative game with a continuum of players in which quantities are the firms' strategies. Note that one of the main advantages of monopolistic competition is that the distinction between price

\footnotetext{
${ }^{1}$ Such factor price equalization always holds when each country has enough labor to support some production of $Z$ for any international allocation of capital, which we assume to hold.
} 
competition and quantity competition becomes immaterial. Indeed, being negligible to the market, each firm behaves as a monopolist on its residual demand, which makes it indifferent between using price or quantity as a strategy.

Firms in country $H$ maximize their profit given by

$$
\Pi_{H}=\theta\left(p_{H H}-m\right) q_{H H}+(1-\theta)\left(p_{H F}-m-\tau\right) q_{H F}-r_{H} \phi_{H}
$$

with respect to $q_{H H}$ and $q_{H F}$ independently. Because each firm is negligible to the market, it has no impact on the two indices $Q_{H}$ and $Q_{F}$.

Hence, maximizing (3) yields the following profit-maximizing outputs:

$$
q_{H H}\left(Q_{H}\right)=\frac{\alpha-m-\gamma Q_{H H}}{2(\beta-\gamma)} \quad q_{F H}\left(Q_{H}\right)=q_{H H}\left(Q_{H}\right)-\frac{\tau}{2(\beta-\gamma)} .
$$

Symmetric expressions hold for country- $F$ firms. Although each firm is negligible so that its output does not change aggregate market conditions, those conditions influence each firm's optimal strategy. Using (4) as well as the expressions of output aggregates, the (Nash) equilibrium intranational and international quantities are:

$$
q_{H H}^{*}=\frac{2(\beta-\gamma)(\alpha-m)+\gamma(1-\lambda) N \tau}{2(\beta-\gamma)[2(\beta-\gamma)+\gamma N]} \quad q_{F H}^{*}=q_{H H}^{*}-\frac{\tau}{2(\beta-\gamma)} .
$$

Using the equilibrium quantity aggregates $Q_{H}^{*}$ and $Q_{F}^{*}$, it is readily verified that the demands (2) can be expressed as follows:

$$
p_{H H}^{*}=(\beta-\gamma) q_{H H}^{*}+m \quad p_{F H}^{*}=(\beta-\gamma) q_{F H}^{*}+m+\tau .
$$

For bilateral trade to occur for any $0 \leq \lambda \leq 1$, international demands evaluated must be positive. This is satisfied when

$$
\tau<\frac{2(\alpha-m)(\beta-\gamma)}{2(\beta-\gamma)+\gamma N}
$$

which we assume to hold in subsequent developments. Note that (7) implies that $\alpha-m-\tau>0$.

Plugging the equilibrium quantities into (3) and equating profits to zero allows us to express the equilibrium rental rate of capital in country $H$ as follows:

$$
r_{H}^{*}(\lambda)=\frac{\beta-\gamma}{\phi_{H}}\left[\theta\left(q_{H H}^{*}\right)^{2}+(1-\theta)\left(q_{H F}^{*}\right)^{2}\right] .
$$


Finally, let

$$
\Delta r^{*}(\lambda) \equiv r_{H}^{*}(\lambda)-r_{F}^{*}(\lambda)
$$

stand for the rental rate differential of capital between countries $H$ and $F$, which is a continuous function of the capital distribution $\lambda$.

\section{The market outcome}

So far, we have described the optimal choices of consumers and firms for a given spatial allocation $\lambda$ of capital. We now complete the characterization of the spatial equilibrium by determining the value of $\lambda$ for which no agent has an incentive to change her allocation of capital. Because capital is perfectly mobile, its rental rate must be equalized across countries at any interior equilibrium $0<\lambda^{*}<1$ : $r_{H}\left(\lambda^{*}\right)=r_{F}\left(\lambda^{*}\right)$ or, equivalently, $\Delta r^{*}\left(\lambda^{*}\right)=0$.

Unfortunately, the solution with arbitrary fixed costs $\phi_{H}$ and $\phi_{F}$ turns out to be especially cumbersome. This leads us to focus on the special, but relevant, case in which the fixed requirements of capital needed to launch a firm only slightly differ between the two countries: $\phi_{H} \equiv \phi+\varepsilon$ and $\phi_{F} \equiv$ $\phi-\varepsilon$, where $|\varepsilon|$ is very small. In the present context, $\varepsilon$ may be interpreted as a mean-preserving measure of the set-up cost differential between countries $H$ and $F$. Formally, this is equivalent to a small and symmetric perturbation of $\phi_{H}$ and $\phi_{F}$ around the identical technology case.

We define a spatial equilibrium $\lambda_{\varepsilon}^{*}$ associated with the perturbation $\varepsilon$ as a solution to the equation $\Delta r^{*}(\lambda, \varepsilon)=0$. Such an equilibrium exhibits a HME when the country with the larger share of consumption expenditure hosts an even larger share of firms (Helpman and Krugman, 1985). Formally, a HME arises in equilibrium when

$$
\frac{n_{H}^{*}(\varepsilon)}{n_{F}^{*}(\varepsilon)}>\frac{\theta}{1-\theta}
$$

where $n_{H}^{*}$ and $n_{F}^{*}$ are derived from (1) at the spatial equilibrium distribution of capital. As shown by Ottaviano and Thisse (2004), the symmetrictechnology spatial equilibrium $\lambda_{0}^{*}$ satisfying the equation $\Delta r^{*}(\lambda ; 0)=0$ is given by

$$
\lambda_{0}^{*}=\frac{1}{2}+\frac{2(\beta-\gamma)[2(\alpha-m)-\tau] \phi}{K \gamma \tau}\left(\theta-\frac{1}{2}\right)>\theta>1 / 2 .
$$

The first inequality holds since $2(\alpha-m)-\tau>0$ whenever international trade occurs. Hence, in the symmetric-technology case the larger country hosts a 
more than proportional share of the imperfectly competitive industry, thus confirming Helpman and Krugman's (1985) finding.

Our aim in the remainder of this section is to assess how the spatial equilibrium changes under a small asymmetry $\varepsilon$ in fixed costs. Formally, we investigate how the asymmetric-technology spatial equilibrium $\lambda_{\varepsilon}^{*}$, associated with $\varepsilon$, compares with $\lambda_{0}^{*}$. Somewhat unexpectedly, two opposite effects are at work. First, when $\varepsilon>0$, set-up costs in country $H$ (resp., $F$ ) become larger (resp., lower), thus making country $H$ less attractive for any given distribution $\lambda$ of capital. Second, the total mass of varieties in the economy decreases with $\varepsilon$ in the vicinity of $\varepsilon=0$. Indeed, differentiating the total mass of firms

$$
N=n_{H}+n_{F}=\frac{\lambda K}{\phi+\varepsilon}+\frac{(1-\lambda) K}{\phi-\varepsilon}
$$

with respect to $\varepsilon$ yields

$$
\frac{d N}{d \varepsilon}=-\frac{\lambda K}{(\phi+\varepsilon)^{2}}+\frac{(1-\lambda) K}{(\phi-\varepsilon)^{2}} .
$$

When $\varepsilon=0$, the sign of this derivative depends on the sign of $(1-2 \lambda) K / \phi^{2}$. As shown by (10), this is always negative at the spatial equilibrium $\lambda_{0}^{*}$ when country $H$ is larger than country $F$. Stated differently, the decrease in the number of firms in $H$ exceeds the increase observed in $F$. Everything else being equal, this makes country $H$ (resp., $F$ ) less (resp., more) competitive, thus raising (resp., lowering) local firms' operating profits. Clearly, the equilibrium spatial distribution of firms accounts for these two opposite effects.

The differential $\Delta r^{*}$ corresponding to $\phi_{H} \equiv \phi+\varepsilon$ and $\phi_{F} \equiv \phi-\varepsilon$ depends on $\varepsilon$ and may be rewritten as its Taylor expansion around $\left(\lambda_{0}^{*}, 0\right)$ :

$$
\begin{aligned}
\Delta r^{*}\left(\lambda_{\varepsilon}^{*}, \varepsilon\right) & =\Delta r^{*}\left(\lambda_{0}^{*}, 0\right)+\varepsilon \frac{\partial\left(\Delta r^{*}\right)}{\partial \varepsilon}\left(\lambda_{0}^{*}, 0\right) \\
& +\left(\lambda_{\varepsilon}^{*}-\lambda_{0}^{*}\right) \frac{\partial\left(\Delta r^{*}\right)}{\partial \lambda}\left(\lambda_{0}^{*}, 0\right)+o\left(\lambda_{\varepsilon}^{*}-\lambda_{0}^{*}, \varepsilon\right)
\end{aligned}
$$

where

$$
\lim _{\|x\| \rightarrow 0} \frac{o(x)}{\|x\|}=0
$$

with $\|x\|$ being the norm of the vector $x=\left(\lambda_{\varepsilon}^{*}-\lambda_{0}^{*}, \varepsilon\right)$. Then, since $\Delta r^{*}\left(\lambda_{\varepsilon}^{*}, \varepsilon\right)=0$ and $\Delta r^{*}\left(\lambda_{0}^{*}, 0\right)=0$ by definition of a spatial equilibrium 
we have

$$
\lambda_{\varepsilon}^{*}-\lambda_{0}^{*}=-\varepsilon \frac{\frac{\partial\left(\Delta r^{*}\right)}{\partial \varepsilon}\left(\lambda_{0}^{*}, 0\right)}{\frac{\partial\left(\Delta r^{*}\right)}{\partial \lambda}\left(\lambda_{0}^{*}, 0\right)}+o\left(\lambda_{\varepsilon}^{*}-\lambda_{0}^{*}, \varepsilon\right) .
$$

Hence, for $\varepsilon$ sufficiently small, the sign of $\lambda_{\varepsilon}^{*}-\lambda_{0}^{*}$ is given by the sign of the first term on the right hand side. ${ }^{2}$ It is readily verified that

$$
\frac{\partial\left(\Delta r^{*}\right)}{\partial \lambda}\left(\lambda_{0}^{*}, 0\right)=\frac{-K \gamma \tau^{2}}{2(\beta-\gamma) \phi[K \gamma+2(\beta-\gamma) \phi]}<0
$$

Thus, it remains to determine to sign of $\partial\left(\Delta r^{*}\right) / \partial \varepsilon$ in order to compare $\lambda_{\varepsilon}^{*}$ and $\lambda_{0}^{*}$. Standard calculations, developed in the Appendix, show that $\partial\left(\Delta r^{*}\right) / \partial \varepsilon<0$ for all admissible parameter values when $\theta>1 / 2$. Hence, we have shown the following result:

Proposition 1 For a sufficiently small $\varepsilon \gtreqless 0, \lambda_{\varepsilon}^{*} \lesseqgtr \lambda_{0}^{*}$ for all values of $\theta \geq 1 / 2$ and for all values of $\tau$ satisfying (7).

The economic intuition underlying this proposition is as follows. When $\varepsilon>0$, say, the total mass of firms in the economy decreases which, ceteris paribus, tends to raise the equilibrium prices and operating profits in both countries (via a standard pro-competitive effect). Yet, the return per unit of capital employed in the larger country $H$ rises less (or even falls) than that in the smaller country $F$, because of the larger capital requirement. This triggers a reallocation of capital from the larger to the smaller country, thereby raising prices and operating profits in the former, while decreasing them in the latter. Capital market clearing then implies that the share of firms in country $F$ rises, whereas that in country $H$ falls. ${ }^{3}$ Note finally that, by continuity, the HME still arises when $\varepsilon$ is sufficiently small. Stated differently, when asymmetries in fixed costs are not too important, the larger country still hosts a more than proportional share of the mobile industry.

Let us conclude this section by briefly pointing out what may happen when $\varepsilon>0$ takes larger values. As mentioned above, the analytical treatment of the general case appears to be too cumbersome to lead to a clear-cut

\footnotetext{
${ }^{2}$ This comes from (12) and the continuity of $\lambda_{\varepsilon}^{*}$ with respect to $\varepsilon$.

${ }^{3}$ As shown by Ottaviano and van Ypersele (2005), a similar effect arises when the two countries have different tax rates on the returns to capital, the country having the higher tax rate loosing firms. Yet, the tax-game outcome is still such that the larger country hosts a more than proportionate industry share. Note that in our setting the mass of firms is no longer fixed, which allows for additional competition effects as the total size of the industry changes.
} 
answer. However, the analysis of the following numerical example suffices to show that a reverse HME may arise. Let $\alpha=2, \beta=1, \gamma=0.7, K=5$, $\phi=1, m=0.3, \tau=0.2$ and $\theta=0.6$. One can verify that $n_{H}^{*} / n_{F}^{*}-\theta /(1-\theta)$ is a decreasing function of $\varepsilon$ even for large perturbations. As stated above, the HME still holds when the set-up costs in the two countries are sufficiently similar because $\lambda_{0}^{*}-\theta>0$. However, once the gap in set-up costs becomes sufficiently large, the country hosting the larger share of firms may be the small one. In our numerical example, this happens should the small country have set-up costs about more than $\varepsilon>0.093$ less than the large one.

\section{What is the optimal policy?}

In what follows, we superscript the first-best values of the variables with $f$. As shown by Ottaviano et al. (2002), the consumer surplus in country $H$ is as follows:

$$
\begin{aligned}
S_{H}\left(n_{H}, n_{F}\right)= & \frac{\alpha^{2} N}{2 \Gamma}-\frac{\alpha}{\Gamma}\left(n_{H} p_{H H}+n_{F} p_{F H}\right)+\frac{1}{2(\beta-\gamma)}\left(n_{H} p_{H H}^{2}+n_{F} p_{F H}^{2}\right) \\
& -\frac{\gamma}{2(\beta-\gamma) \Gamma}\left(n_{H} p_{H H}+n_{F} p_{F H}\right)^{2},
\end{aligned}
$$

with $\Gamma \equiv \beta+(N-1) \gamma>0$. Because utilities are quasi-linear, they are transferable so that the planner maximizes the following (utilitarian) social welfare function:

$$
\begin{aligned}
W(\lambda, \varepsilon)= & \theta S_{H}(\lambda, \varepsilon)+(1-\theta) S_{F}(\lambda, \varepsilon)+\lambda K r_{H}(\lambda, \varepsilon) \\
& +(1-\lambda) K r_{F}(\lambda, \varepsilon)+\text { constant. }
\end{aligned}
$$

Marginal cost pricing implies that $p_{H H}=p_{F F}=m$ and $p_{H F}=p_{F H}=m+\tau$, which then yields $r_{H}=r_{F}=0$. Setting prices equal to marginal costs, Ottaviano and van Ypersele (2005) show that the first-best spatial allocation $\lambda$ associated with $\varepsilon=0$ is given by

$$
\lambda_{0}^{f}=\frac{1}{2}+\frac{(\beta-\gamma)[2(\alpha-m)-\tau] \phi}{K \gamma \tau}\left(\theta-\frac{1}{2}\right) \leq \lambda_{0}^{*}
$$

whenever $\theta \geq 1 / 2$. This shows that the market outcome yields too much agglomeration in the larger country with respect to the first-best, so that the welfare-maximizing planner will choose an allocation of capital that is closer to symmetry than the market outcome. Besides the standard production 
and consumption distortions under imperfect competition, another cause of inefficiency is that firms face a lower elasticity of demand in the larger market in the presence of trade costs. Firms, therefore, dump their product into the other country, which leads to wasteful trade in the presence of trade costs.

In this section, we revisit the first-best outcome in the presence of small asymmetries in fixed costs. More precisely, we assume that the planner is able to: (i) set prices equal to marginal costs and use lump sum transfers to compensate firms for losses; and (ii) to choose the spatial allocation $\lambda^{f}$ of capital as well as the mean-preserving degree $\left|\varepsilon^{f}\right|<\phi$ of asymmetry. Let

$$
n_{H}^{f}=\frac{\lambda^{f} K}{\phi+\varepsilon^{f}} \quad \text { and } \quad n_{F}^{f}=\frac{\left(1-\lambda^{f}\right) K}{\phi-\varepsilon^{f}}
$$

stand for the welfare maximizing mass of firms in the two countries when the difference in fixed costs is given by $2 \varepsilon^{f}$. Clearly, $\varepsilon^{f}=0$ corresponds to the case in which there are no differences in technologies and set-up costs between the two countries. As shown by (14), this never corresponds to a welfare-maximizing choice. The question is then: will the planner choose $\varepsilon>0$ and favor the smaller country, or will he choose $\varepsilon<0$ and favor the larger country?

Given the result in (14), one might think that the answer implies $\varepsilon^{f}>0$ because the first-best involves less agglomeration than the market outcome. Yet, as shown in the previous section, choosing $\varepsilon>0$ reduces the total mass of varieties in the global economy. Since consumers value variety, this is welfare-deteriorating. Clearly, the optimal allocation $\left(\lambda^{f}, \varepsilon^{f}\right)$ encapsulates both effect and solves the trade-off between product variety and spatial inequality.

The first-order necessary conditions for $\left(\lambda^{f}, \varepsilon^{f}\right)$ to be a first-best allocation are:

$$
\begin{aligned}
& \frac{\partial W}{\partial \lambda}\left(\lambda^{f}, \varepsilon^{f}\right)=0 \\
& \frac{\partial W}{\partial \varepsilon}\left(\lambda^{f}, \varepsilon^{f}\right)=0 .
\end{aligned}
$$

As in the previous section, we focus on the case of sufficiently small values of $\varepsilon$.

To begin with, note that the unique solution to condition (15) with $\varepsilon=0$ is given by (14). Substituting this solution into condition (16) yields, after 
some tedious calculations, the following expression:

$$
\begin{aligned}
\frac{\partial W}{\partial \varepsilon}\left(\lambda_{0}^{*}, 0\right) & =-\frac{(\beta-\gamma)(2 \theta-1)(2 \xi-\tau) \phi}{4 K \gamma \tau}\left\{(K \gamma \tau)^{2}+2 K(\beta-\gamma) \gamma \tau^{2} \phi\right. \\
& \left.+(\beta-\gamma)^{2}\left[16 \xi(1-\theta) \theta(\xi-\tau)+(1+4(1-\theta) \theta) \tau^{2}\right] \phi^{2}\right\}<0
\end{aligned}
$$

where the inequality results from $\theta>1 / 2$ and the trade feasibility condition $\xi \equiv \alpha-m-\tau>0$. This proves the following:

Proposition 2 The symmetric technology case $\varepsilon^{f}=0$ is never a welfaremaximizing choice. Furthermore, the planner chooses some $\varepsilon^{f}<0$ and, therefore, favor more agglomeration in the larger country.

Proposition 2 suffices to show that the negative impact of decreased variety more than offsets the positive impact of a more even spatial configuration. As can be seen from the expression of $\partial W / \partial \varepsilon$, the symmetry vs variety trade-off vanishes when both countries have approximately the same size (i.e., $\theta$ close to $1 / 2$ ) and/or when products are almost homogenous (i.e., $\beta-\gamma$ close to 0$)$. In such circumstances, the variety effect disappears and we fall back on the 'symmetric' first-best in which the planner chooses a more even spatial distribution of industry.

This result also shows that when countries have different sizes and consumers have a love for variety, two conditions that are quite likely to hold, the optimal spatial allocation of capital may well involve more agglomeration in a first-best setting when this allows for an increase in the mass of varieties in the global economy, an effect that is highlighted in regional growth theory (see, e.g., Baldwin and Martin, 2004).

\section{Concluding remarks}

This note has two main implications. First, we have shown that spatial inequalities may be desirable when they lead to more product variety in a world in which consumers exhibit a love for variety. Since the EU is committed to an explicit social cohesion objective, as clearly spelled-out by Article 130a of the Amsterdam Treaty of 1997 and shown by the importance of Structural Funds, our results highlight once more that this equity objective is likely to conflict with the search for global efficiency. Hence, the search for efficiency, which has motivated for example the endorsement of the European Charter for Small Enterprises at the Feira European Council in June 2000, may itself interfere with the social cohesion objective of the Amsterdam Treaty. 
Second, when both technology differences and increasing returns interact, the size effect associated with the HME may actually not manifest itself in the observed spatial equilibrium structure. More precisely, we have seen that the advantage of the small country in terms of fixed and set-up costs impacts negatively on the HME by reducing the share of capital in the large country. Stated differently, capital is naturally attracted to regions where it may easily enter the market since this raises its per-unit return. Hence, ex post we may observe that the more efficient country is the net exporter of the differentiated good even if its market size is quite small. This suggests that controlling for differences in technology and barriers to entry should be an important ingredient of empirical tests of the HME.

\section{References}

[1] Baldwin, R.E. and P. Martin (2004) Agglomeration and regional growth. In J.-F. Thisse and J.V. Henderson (eds.) Handbook of Regional and Urban Economics, vol. 4. Amsterdam: North Holland, pp. 2671-2711.

[2] Djankov, S., R. La Porta, F. Lopez de Silanes and A. Shleifer (2002) The regulation of entry, Quarterly Journal of Economics 117, 1-37.

[3] Engel, C. and J.H. Rogers (1996) How wide is the border? American Economic Review 86, 1112-1125.

[4] European Commission (2002) Benchmarking the administration of business start-ups. Entreprise directorate-general, Centre for Strategy and Evaluation Services, Brussels.

[5] GEM (2000) Global Entrepreneurship Monitor: 2000 Executive Report. The GEM Consortium. The full version of the report is available online at http://www.gemconsortium.org.

[6] GEM (2002) Global Entrepreneurship Monitor: 2002 Executive Report. The GEM Consortium. The full version of the report is available online at http://www.gemconsortium.org.

[7] Haskel, J. and H. Wolf (2001) The law of one price - A case study, Scandinavian Journal of Economics 103, 545-558.

[8] Head, K. and T. Mayer (2000) Non-Europe. The magnitude and causes of market fragmentation in the EU, Weltwirtschaftliches Archiv 136, 284-314. 
[9] K. Head, T. Mayer and J. Ries (2002) On the pervasiveness of home market effects, Economica 69, 371-390.

[10] Helpman, E. and P. Krugman (1985) Market Structure and Foreign Trade. Cambridge, MA: MIT Press.

[11] Krugman, P.R. (1980) Scale economies, product differentiation, and the pattern of trade, American Economic Review 70, 950-959.

[12] Krugman, P.R. (1991) Geography and Trade. Cambridge, MA: MIT Press.

[13] Ottaviano, G.I.P., T. Tabuchi and J.-F. Thisse (2002) Agglomeration and trade revisited, International Economic Review 43, 409-436.

[14] Ottaviano, G.I.P. and J.-F. Thisse (2002) Integration, agglomeration and the political economics of factor mobility, Journal of Public Economics 83, 429-456.

[15] Ottaviano, G.I.P. and J.-F. Thisse (2004) Agglomeration and economic geography. In J.-F. Thisse and J.V. Henderson (eds.) Handbook of Regional and Urban Economics, vol. 4. Amsterdam: North Holland, pp. 2563-2608.

[16] Ottaviano, G.I.P. and T. van Ypersele (2005) Market size and tax competition. Forthcoming in Journal of International Economics.

\section{Appendix:}

In this appendix, we show that

$$
\frac{\partial\left(\Delta r^{*}\right)}{\partial \varepsilon}\left(\lambda_{0}^{*}, 0\right)<0
$$

for all admissible parameter values. Evaluating $\Delta r^{*}$ at the equilibrium prices and using (10), some tedious but standard calculations show that

$$
\begin{aligned}
\frac{\partial\left(\Delta r^{*}\right)}{\partial \varepsilon}\left(\lambda_{0}^{*}, 0\right) & =-\frac{1}{C}\left\{\frac{(K \gamma)^{3} \tau^{2}}{\phi^{2}}+\frac{4(K \gamma)^{2}(\beta-\gamma) \tau^{2}}{\phi}\right. \\
& -16(\beta-\gamma)^{3}(1-2 \theta)^{2}(2(m-\alpha)+\tau)^{2} \phi \\
& +4 K(\beta-\gamma)^{2} \gamma[8(\alpha-m)(1+6(\theta-1) \theta)(\alpha-m-\tau) \\
& \left.\left.+(1+12(\theta-1) \theta) \tau^{2}\right]\right\}
\end{aligned}
$$


where

$$
C=8 K(\beta-\gamma) \gamma[K \gamma+2(\beta-\gamma) \phi]^{2}>0
$$

is a bundle of parameters independent of $\theta$ and $\tau$. It is readily verified that

$$
\frac{\partial^{2}\left(\Delta r^{*}\right)}{\partial \varepsilon \partial \theta}\left(\lambda_{0}^{*}, 0\right)=\frac{2(\beta-\gamma)(2 \theta-1)[2(m-\alpha)+\tau]^{2}[3 K \gamma+4(\beta-\gamma) \phi]}{K \gamma[K \gamma+2(\beta-\gamma) \phi]^{2}}>0
$$

since $\theta>1 / 2$, thus showing that the derivative of $\Delta r^{*}$ with respect to $\varepsilon$ is increasing in $\theta$. Note that, as shown by (10), $\lambda_{0}^{*}>1$ when $\theta=1$. Since this is impossible because $\lambda \leq 1$, in order to evaluate the derivative of $\Delta r^{*}$ with respect to $\varepsilon$ at $\theta=1$, we have to recalculate this derivative by substituting $\lambda_{0}^{*}=1$ instead of (10). Straightforward calculation shows that

$$
\left.\frac{\partial\left(\Delta r^{*}\right)}{\partial \varepsilon}(1,0)\right|_{\theta=1}<0
$$

Since $\Delta r^{*}$ is twice continuously differentiable with respect to $\varepsilon$, since the derivative is increasing with respect to $\theta$, and since it is negative for $\theta=1$, we may conclude that it is negative for all admissible parameter values and all $1 / 2<\theta \leq 1$. This proves our claim. 
Département des Sciences Économiques de l'Université catholique de Louvain

Institut de Recherches Économiques et Sociales

Place Montesquieu, 3

1348 Louvain-la-Neuve, Belgique 